\title{
Distribution of neurotransmitters in the sheep brain
}

\author{
Y. Tillet \\ Laboratoire de Neuroendocrinologie Sexuelle, Station de Physiologie de la Reproduction des \\ Mammiferes Domestiques, INRA, 37380 Nouzilly, France
}

\begin{abstract}
Although the general organization of the sheep brain is similar to that of other mammals, there are species differences in the fine architecture and neurotransmitter distribution. In sheep, perikarya are generally scattered, unlike the situation in rodents where they are clustered. The same organization is observed in cows and primates. The density of neurones immunoreactive for tyrosine hydroxylase in the dorsorostral diencephalon of sheep is lower than in rodents; AI4 and A15 dopaminergic cell groups do not present a dorsal part. Only one adrenergic group, $\mathrm{C} 2$, is observed in the dorsomedial medulla oblongata. $\mathrm{GnRH}$-immunoreactive neurones are mainly found in the anterior hypothalamic-preoptic areas, a few being present in the mediobasal hypothalamus. The density of several neurones containing neuropeptides (for example vasoactive intestinal polypeptide, cholecystokinin and somatostatin) in the caudal brain of sheep is lower than in other species and in the forebrain of sheep. These differences contribute to different patterns of innervation of brain areas compared with other species. For example, the suprachiasmatic nucleus does not present a dense network of fibres immunoreactive for 5 -hydroxytryptamine and neuropeptide $Y$ as observed in rats. These morphological studies constitute information necessary for further physiological investigations.
\end{abstract}

\section{Introduction}

In sheep, as in other species, neurotransmitters in the brain are involved in the control of physiological cues through endocrine and autonomic regulation. Among the species used to study endocrine regulation, sheep present interesting and specific physiological characteristics. Sheep have been studied extensively and much data about sheep endocrinology contrast with the little information available on the sheep brain, particularly on the distribution of neurotransmitters.

The neuronal function of sheep cannot be inferred from data obtained in other species because of the large differences in the general morphology of the brain between species. Compared with rats, the sheep encephalon presents a large cortex with many circumvolutions, and compared with primates, the sheep brain does not present a flexure of the brainstem. Another large difference between the sheep and rat neuronal organization is the relative scattering of neurones in the nervous tissue. This is also observed in other large mammals such as humans and cattle (Kitahama ef al., 1994). Owing to these differences, distribution of neurotransmitters in the sheep brain has to be specifically studied.

The distribution of neurotransmitters in sheep has been studied by immunohistochemistry and by in situ hybridization and mainly concern monoamines (catecholamines and 5-hydroxytryptamine) and peptides (Table 1). Acetylcholine and amino acid distributions have not been investigated even if these compounds have been identified and sampled in nervous tissue by microdialysis and push-pull methods (Kendrick et al., 1992; Clarke et al, 1993; Lévy et al., 1993).

In this review, only the distribution of perikarya and the main fibre bundles or terminals are considered. Terminal and fibre densities may vary according to the physiological status of the animals and with the sensitivity of the method used. Comparing their distribution from one study to another 
Table 1. Extensive mapping of neurotransmitter containing structures in the sheep brain

\begin{tabular}{|c|c|c|c|}
\hline Transmitters & Structures & Methods & References \\
\hline \multicolumn{4}{|l|}{ Monoamines } \\
\hline $5 \mathrm{HT}$ & Brain $^{a}$ & IHC & Tillet, 1987 \\
\hline TH/DBH & Brain $^{2}$ & IHC & Tillet and Thibault (1989) \\
\hline PNMT & Myelencephalon & $\mathrm{IHC}$ & Tillet (1988) \\
\hline \multicolumn{4}{|l|}{ Neuropeptides } \\
\hline Bendo & Hypothalarnus & IHC & Lehman and Karsch (1993) \\
\hline POMC & Hypothalamus & ISH & Mc Shane et al. (1993) \\
\hline CCK & Brain & IHC & Antonopoulos et al. (1987) \\
\hline $\mathrm{CCK}$ & Hypothalamus & IHC & Marson ef al. (1987) \\
\hline CGRP & Diencephalon & IHC & Herbison et al. (1993a) \\
\hline CRF & Hypothalamus & $\mathrm{IHC}$ & Kolodziejczyk ef al. (1983) \\
\hline CRF & Brain & RIA & Palkovits et al. (1983) \\
\hline CRF & Brain & ISH & Matthews et al. (1991) \\
\hline CRF & Hypothalamus & IHC & Paull ef al. (1982) \\
\hline DYN A & Hypothalamus & IHC & Marson et al. (1987) \\
\hline $\mathrm{GnRH}$ & Hypothalamus & IHC & Hoffman ef al. (1978) \\
\hline GnRH & Hypothalamus & IHC & Polkowska et al. (1980) \\
\hline GnRH & Hypothalamus & IHC & Dees et al. (1981) \\
\hline GnRH & Hypothalamus & IHC & Advis et al. (1985) \\
\hline GnRH & Hypothalamus & IHC & Glas et al. (1986) \\
\hline GnRH & Hypothalamus & $\mathrm{IHC}$ & Lehman et al. (1986) \\
\hline GnRH & Brain & IHC & Caldani ef al. (1988) \\
\hline GnRH & POA & $\mathrm{ISH}$ & Mc Shane et al. (1993) \\
\hline Met-enk & Hypothalamus & IHC & Marson et al. (1987) \\
\hline PPE & Brain & ISH & Matthews et al. (1992) \\
\hline NPY & Hypothalamus & $\mathrm{ISH}$ & Mc Shane et al. (1993) \\
\hline NPY & Brain & IHC & Antonopoulos et al. (1989a) \\
\hline NT & Brain & IHC & Papadopoulos et al (1986a) \\
\hline OT & Brain & IHC/ISH & Broad et al. (1993b) \\
\hline SRIF & Brain & IHC & Papadopoulos et al. (1986b) \\
\hline VIP & Brain & IHC & Antonopoulos et al. (1987) \\
\hline
\end{tabular}

'Except cerebral hemisphere and cerebellum

$\beta$ endo: $\beta$ endorphin; CCK : cholecystokinin; CGRP: calcitonin gene related peptide; CRF: corticotrophin releasing factor; $D B H$ : dopamine $\beta$-hydroxylase; DYN A: dynorphin $A ; G n R H$ : gonadotrophin releasing hormone; IHC: immunohistochemistry; ISH: in silu hybridization; Met-enk: methionine enkephalin; NPY: neuropeptide $Y$; NT: neurotensin; OT: oxytocin: PNMT: phenylethanolamine $N$-methyl transferase; POMC: proopiomelanocortin; PPE: preproenkephalin; RIA: radioimmunoassay: SRIF: somatostatin; TH: tyrosine hydroxylase; VIP: vasoactive intestinal peptide: 5 HT: 5 -hydroxytryptamine.

is difficult, and for that reason they will not be considered here. Most of the studies presented in this review have been performed in the whole brain, while others have been performed only in the anterior hypothalamic-preoptic area, which contains the largest number of different neuromediators (Nieuwenhuys, 1985) and is involved in the regulation of numerous endocrine and autonomic functions.

\section{Monoamines}

\section{5-Hydroxytryptamine}

The presence of neurones containing 5-hydroxytryptamine $(5 \mathrm{HT})$ has been demonstrated by immunohistochemistry with antisera raised against 5HT (Tillet, 1987). 5HT-immunoreactive (IR) 
perikarya are distributed in twelve neuronal groups from the caudal medulla oblongata to the caudal mesencephalon and the pineal gland (Fig. 1). Each group has been classified according to the Swedish nomenclature (Dahlström and Fuxe, 1964) and a nomenclature previously described (Tillet, 1987). Two main areas of $5 \mathrm{HT}$ neurones are observed: in the caudal part of the medulla oblongata (nuclei B1, B2, B3, $\mathrm{SI}$ and S2) and in the rostral part of the brainstem (nuclei B5, B6, B7, B8, B9, S3 and S4).

Groups B1 and B2 are the most caudal groups situated in the nuclei raphes pallidus and obscurus. Neurones of group B1 are in the ventral half of the medulla and neurones of group B2 in the dorsal part, under the central canal around which some labelled perikarya are observed. This latter group actually presents a greater extension in sheep than in rats (Steinbusch, 1981), since $5 \mathrm{HT}$ neurones are observed in the dorsal vagal complex without colchicine treatment.

Group B3 extends to the same level as groups B1, B2, slightly rostrally to B2, at the level of the nucleus reticularis gigantocellularis where some $5 \mathrm{HT}$ neurones are observed. However, neurones of this group extend more laterally compared with those in rodents, since they are seen near the ventrolateral edge of the nucleus reticularis lateralis in sheep.

A group of $5 \mathrm{HT}$ neurones is not found in the nucleus vestibularis corresponding to the group B4 of rats; very few neurones are scattered in this area. This group is also absent from the squirrel monkey (Hubbard and DiCarlo, 1974).

In groups $\mathrm{S}$, and $\mathrm{S}_{2}$ the lateral part of the medulla presents two groups of neurones containing $5 \mathrm{HT}$. The first, S1 (Fig. 2a), is located near the nucleus reticularis lateralis and ventrolateral to the nucleus ambiguus; the second, S2, is situated on each side of the nucleus reticularis gigantocellularis, dorsolateral to the pyramis. The distribution of 5HT neurones in these lateral areas is characteristic of sheep, since in rats the same structures contain only a few scattered perikarya, which do not constitute anatomical entities as in other members of group $B$.

Groups B5, B6, B7 and B8 contain an important population of $5 \mathrm{HT}$ neurones in the sheep as in other species. Group B5 extends between the fasciculi longitudinalis medialis (FLM) and the transverse pontine fibres. Dorsally to this group, between the FLM and the fourth ventricle, a small group of neurones constitutes group B6. Just rostrally to this gathering, the greatest density of $5 \mathrm{HT}$ neurones is found in the raphe dorsalis and in the mesencephalic central grey. In group B7, rounded neurones are stained slightly less intensely than they are in other groups. This contrasts to the neurones situated above this group in group B8 where 5HT neurones are mainly bipolar and their long axes vertical. These four groups are also observed in other mammals. However, in sheep, boundaries between these groups cannot be well delineated, and a clear-cut distinction is more difficult to observe than it is in rats. Compared with primates (Kawata et al., 1984), group B8 is seen in a narrower space in sheep. Neurones of group B8 send projections to the medial preoptic area (Tillet, 1992).

Group S3 is composed of multipolar 5HT neurones distributed in the lateral part, caudal to the locus coeruleus. This group was also observed in other species using immunohistochemistry but not using formaldehyde-induced fluorescence. Perikarya of neurones containing $5 \mathrm{HT}$ have a shape similar to that of noradrenergic cells but 5HT neurones are not observed in the sheep locus coeruleus, in contrast to the situation in other species (Sladek and Walker, 1977; Léger and Descarries, 1978; Léger et al., 1979).

Group $S_{4}$ is situated on each side of the interpeduncular nucleus (Fig. 2b) and has been observed in other species. Neurones of this group are oriented parallel to the ventral edge of the mesencephalon, in sheep and rats (Steinbusch, 1981). However, in contrast to the latter species, no perikarya are observed in the interpeduncular nucleus. These neurones are always intensely stained and some project to the medial preoptic area (Tillet, 1992).

Group B9 extends dorsolaterally to the decussation of the cerebral peduncles. In sheep it is characterized by a low density of perikarya and by a more lateral distribution than in rats (Steinbusch, 1981).

Group S5 consists of pinealocytes that are homogeneously labelled throughout the pineal gland. In sheep, the pineal almost exclusively contains pinealocytes, in contrast to many other species.

Fig. 1. Schematic drawings of successive frontal sections through the sheep brain, from rostral to caudal levels. The distribution of TH-, DBH- and 5HT-IR neurones (adapted from Tillet and Thibault, 1989 and Tillet, 1987, respeciively). For abbreviations, see Table 2. 


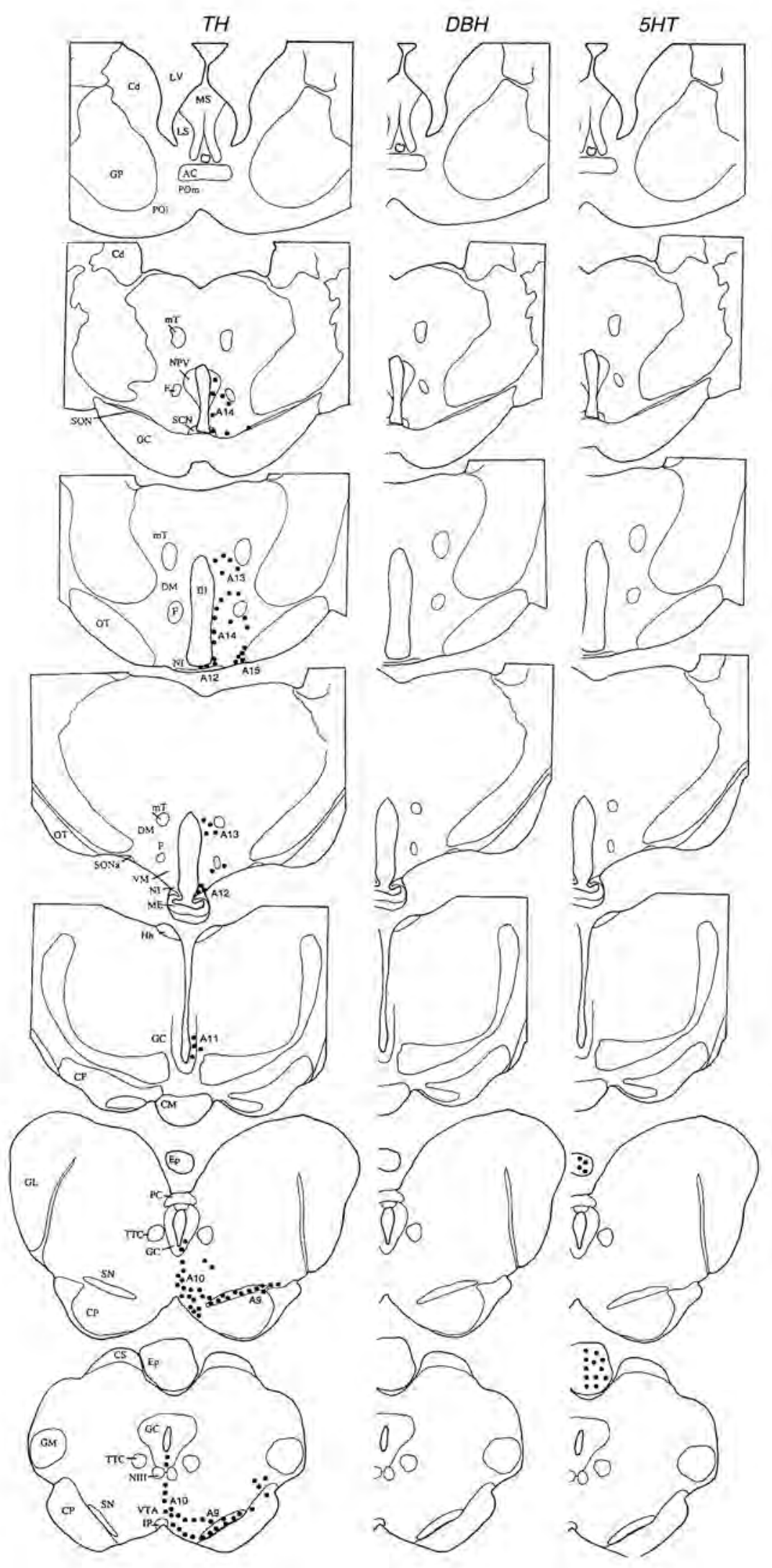







Table 2. Abbreviations used in the figures

\begin{tabular}{|c|c|c|c|}
\hline$A C$ & anterior commissure & MS & medial septum \\
\hline$A m B$ & basal nucleus of the amygdala & $\mathrm{mT}$ & mammillothalamic tract \\
\hline AmC & central nucleus of the amygdala & NA & nucleus ambiguus \\
\hline AmCd & caudal nucleus of the amygdala & $\mathrm{NCu}$ & nucleus cuneiformis \\
\hline AmCo & cortical nucleus of the amygdala & NI & infundibular nucleus \\
\hline AmL & lateral nucleus of the amygdala & NIII & nucleus nervi occulomotorii \\
\hline$A m M$ & median nucleus of the amygdala & NP & nucleus pontis \\
\hline AP & area postrema & $\mathrm{NPe}$ & nucleus periventricularis hypothalami \\
\hline $\mathrm{BC}$ & brachium conjunctivum & NPV & nucleus paraventricularis hypothalami \\
\hline BNST & bed nucleus of the stria terminalis & NRGC & nucleus reticularis paragigantocellularis \\
\hline & canalis centralis & NRL & nucleus reticularis lateralis \\
\hline $\mathrm{Cd}$ & caudate nucleus & NTS & nucleus tractus solitarius \\
\hline Cer & cerebellum & NTSV & nucleus tractus spinalis nervi trigemini \\
\hline $\mathrm{CI}$ & colliculi inferior & NVII & nucleus nervi fascialis \\
\hline $\mathrm{CM}$ & mammillary nucleus & NX & nucleus nervi vagi \\
\hline $\mathrm{CP}$ & cerebral peduncle & NXII & nucleus nervi hypoglossii \\
\hline CS & colliculi superior & $O C$ & optic chiasma \\
\hline DM & dorsal hypothalamic nucleus & Ol & nuclei olivares \\
\hline DPC & decussatio pedunculorum cerebellarium superiorum & OT & optic tract \\
\hline Ep & epiphysis & PBL & nucleus parabrachialis lateralis \\
\hline $\mathrm{F}$ & fornix & PC & pedunculus cerebri \\
\hline FLM & fasciculus longitudinalis medialis & $\mathrm{PCl}$ & pedunculus cerebellaris inferior \\
\hline FPT & pontine transverse fibres & PH & nucleus prepositus hypoglossii \\
\hline FRM & mesencephalic reticular formation & PM & nucleus premammillaris \\
\hline GC & central grey & POI & lateral preoptic area \\
\hline GL & lateral geniculate nucleus & POm & medial preoptic area \\
\hline GM & median geniculate nucleus & Put & putamen \\
\hline GP & globus pallidus & Py & pyramis \\
\hline $\mathrm{H}$ & hippocampus & $\mathrm{SCN}$ & nucleus suprachiasmaticus \\
\hline $\mathrm{Hb}$ & habenular nucleus & SN & substantia nigra (pars compacta) \\
\hline III & third ventricle & SON & nucleus supraopticus \\
\hline IP & interpeduncular nucleus & SONa & nucleus supraopticus accessorius \\
\hline IV & fourth ventricle & TMV & tractus mesencephalicus nervi trigemini \\
\hline LC & locus coeruleus & TS & tractus solitarius \\
\hline LH & lateral hypothalamic area & TSV & tractus spinalis nervi trigemini \\
\hline LL & lateral lemniscus & TTC & tractus tegmentalis centralis \\
\hline LS & lateral septum & VM & nucleus hypothalamicus ventromedialis \\
\hline LV & lateral ventricle & VTA & ventral tegmental area \\
\hline ME & median eminence & $\mathrm{ZI}$ & zona incerta \\
\hline
\end{tabular}

No $5 \mathrm{HT}$ perikarya are observed in more rostral structures such as the diencephalon.

With respect to $5 \mathrm{HT}$ innervation of the diencephalon, a striking difference is observed in the sheep suprachiasmatic nucleus (SCN) which fails to present a dense innervation as in rats. The same density of fibres is found inside and outside the nucleus. The same pattern of innervation is observed in monkeys (Kawata ef al., 1984).

\section{Catecholamines}

The distribution of catecholamine-containing structures has been studied using antisera raised against catecholamine synthesizing enzymes (TH: tyrosine hydroxylase; AADC; aromatic 1 -amino acid decarboxylase; DBH: dopamine $\beta$-hydroxylase; PNMT: phenylethanolamine $N$-methyltransferase), but also with antisera raised against dopamine (DA) and noradrenaline. In sheep, classification of 

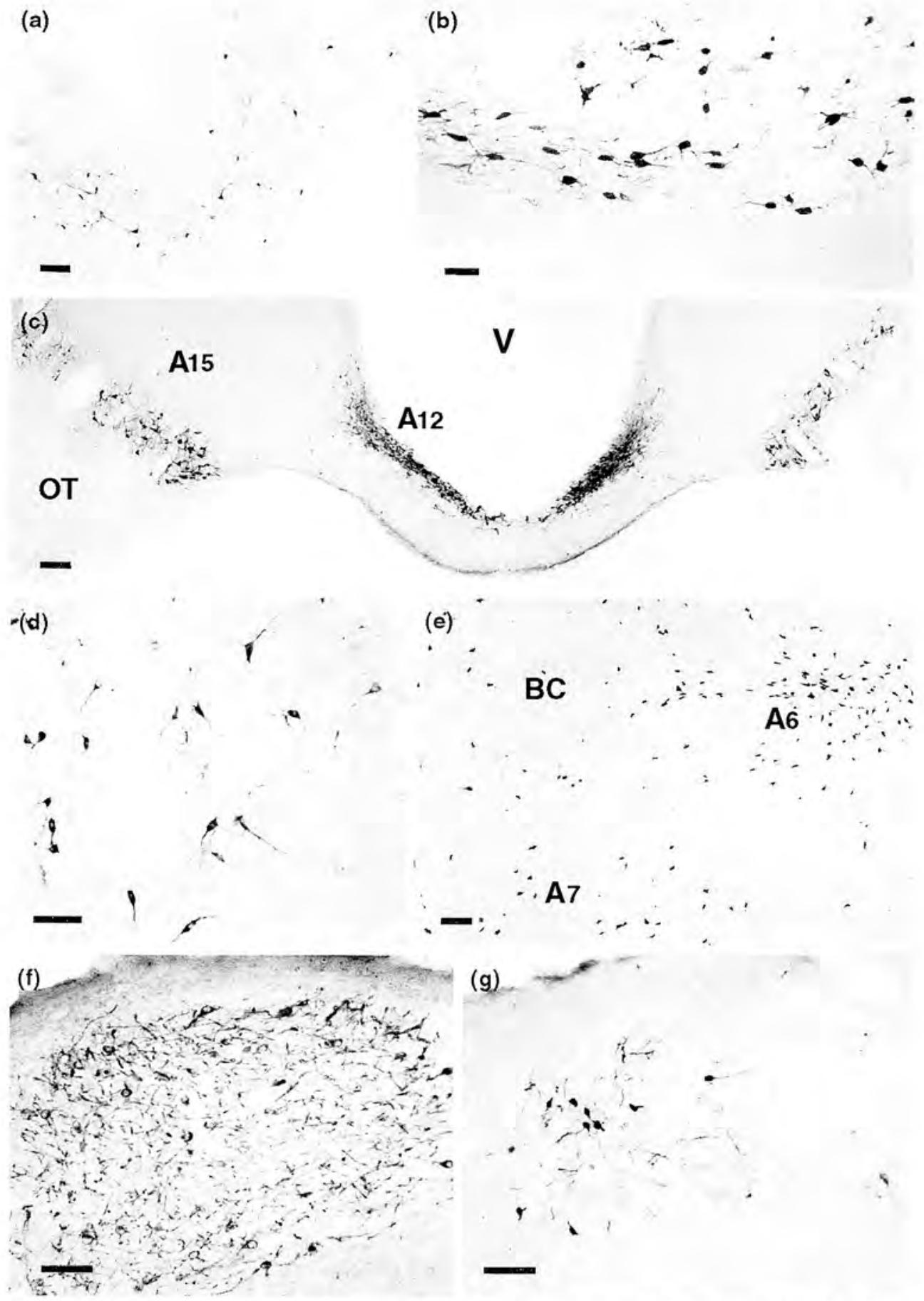

Fig. 2. 5-Hydroxytryptamine immunoreactive (5HT-IR) neurones situated in (a) group S1 in the lateral medulla oblongata and (b) in group S4 on each side of the interpeduncular nucleus. (c) Photomontage showing tyrosine hydroxylase immunoreactive (TH-IR) neurones of the infundibular nucleus (A12) and of group A15 in the ventral hypothalamus. (d) TH-IR neurones of group A10 (dorsocaudal part) situated in the nucleus raphe dorsalis. (e) Dopamine $\beta$-hydroxylase immunoreactive (DBH-IR) neurones of groups A6/A7 note the dispersion of labelled neurones in $A 6$ and $A 7$. (f) DBH-IR neurones in groups $A 2 / C 2$ in the dorsomedial medulla; $(\mathrm{g})$ serial section showing phenylethanolamine $\mathrm{N}$-methyltransferase immunoreactive (PNMT-IR) neurones of the same area. BC: brachium conjunctivum; OT: optic tract; V: third ventricle. Scale bars in (a), (c), (e) $250 \mu \mathrm{m}$; (b), (d), (f), (g) $100 \mu \mathrm{m}$. 
catecholamine cell groups can be made according to the Swedish nomenclature established in rats (Dahlström and Fuxe, 1964; Hökfelt et al., 1984).

Dopamine. Cell groups containing dopamine extend to the mesencephalon and the diencephalon.

Groups $A 8$ and $A 9$ are the most caudal dopaminergic cell groups. Group A8 is situated dorsolaterally to the substantia nigra and is made of sparsely distributed neurones. Its boundaries with group A9 are not distinct, but are easier to observe than in A9 of primates (Felten and Sladek, 1983). In sheep, group A9 is composed of perikarya compacted in a thin layer in the pars compacta of the substantia nigra, and the bipolar neurones are oriented parallel to the ventral part of the mesencephalon. Tyrosine hydroxylase immunoreactive (TH-IR) neurones are distributed more rostrally than they are in rats and cells containing dopamine are more compactly clustered than they are in primates and rodents (Pearson et al, 1983; Hökfelt et al., 1984). None or very few perikarya are found in the sheep pars reticulata.

In sheep and rats (Hökfelt et al., 1984), most neurones of group A10 are found in the ventral tegmental area (VTA), but others are observed in the raphe dorsalis (AIO dorsocaudal), near the habenula (A10 dorsorostral) and laterally to the mammillary bodies (AIO ventrorostral). As in rats, the presence of dopamine in these subdivisions has not been checked. Compared with rodents, this group seems to be more heterogeneous, because of the dispersion of its different components. In sheep, the dorsocaudal part (Fig. 2 d) presents a higher concentration of perikarya than in rodents or primates, and in humans few neurones are visible (Kitahama ef al., 1994).

Groups A11 and A13 are found around the caudal part of the third ventricle and dorsolaterally to the third ventricle, respectively. Compared with rats (Hökfelt et al., 1984), group A11 contains few perikarya and does not extend laterally from the ventricle. Group A13 is mainly localized in the dorsolateral hypothalamus caudal to the paraventricular nucleus; few neurones are stained in an area corresponding to the zona incerta. In contrast to their localization in rats, both groups form a unique gathering.

Group A12 is a dense cluster of TH-IR neurones in the infundibular nucleus (related to the arcuate nucleus of rodents), which is characterized in sheep by the presence of neurones containing dopamine in the dorsal area of the median eminence, in the floor of the third ventricle (Fig. $2 \mathrm{c}$ ). In sheep and rats, a small percentage of neurones containing dopamine (less than 10\%) are immunostained with antioestradiol receptors or concentrate $\left[{ }^{3} \mathrm{H}\right]$ oestradiol (Sar, 1983; Batailler et al, 1992; Lehman and Karsch, 1993).

Group AI4 is found around the rostral part of the third ventricle. In sheep, neurones of this group are localized in a narrow strip along the wall of the ventricle and it does not extend as laterally as it does in rats (Hökfelt et al., 1984). Neurones are mainly bipolar and oriented parallel to the wall of the ventricle. Some of the TH-IR neurones do not contain AADC (Y. Tillet, J. Thibault and M. Krieger, unpublished data), which makes the ability of these neurones to synthesize dopamine questionable.

Group AI5 contains large TH-IR neurones clustered in the lateral retrochiasmatic area (Fig. 2c). In contrast to the situation in rats and cats (Kitahama et al., 1990), this group presents only a ventral part: perikarya containing dopamine are not observed around the anterior commissure. In sheep, the dopaminergic nature of this group is demonstrated using anti-AADC and anti-DA (Tillet $e t$ al, 1990), whereas in rats dopamine is not found and neurones appear to synthesize only L-DOPA (Tison et al., 1990). In contrast to primates, dense gatherings of TH-IR neurones are not found in both supraoptic (SON) and paraventricular (PVN) nuclei of sheep (Li et al., 1988; Panayotacopoulou et al., 1991). In sheep and cats, group A15 sends efferent fibres towards the neural lobe of the pituitary (Luppi ef al., 1986; V. Gayrard, J. C. Thiéry, J. Thibault and Y. Tillet, unpublished data),

Group AI6 consists of TH-IR perikarya of the olfactory bulb (Tillet et al., 1987). As in other species, most dopaminergic neurones are found around glomeruli, but all other layers contain TH-IR cell bodies except the anterior olfactory nucleus, in contrast to their localization in hamsters (Davis and Macrides, 1983). The accessory olfactory bulb contains a few TH-IR cells in the glomerular layer, as in other species. 
Noradrenaline. Groups A1 and A2 are the most caudal noradrenergic groups observed in the ventrolateral and dorsomedial part of the medulla oblongata, respectively, in sheep (Fig. 2f). Perikarya of group A2 are distributed around the central canal and on each side of the caudal part of the fourth ventricle near the area postrema. In sheep, a lower density of IR perikarya is found in both groups than in humans in which labelled cells in the reticular formation form a band connecting the dorsomedial and ventrolateral medulla (Pearson et al, 1983, 1990). In sheep, they do not extend to the more dorsal part of the reticular formation. A similar distribution is observed in cattle and pigs (Kitahama et al., 1994). In sheep and rats (Sakumoto et al., 1978) group AI sends fibres to the medial preoptic area (Tillet et al., 1993).

As in cats and humans (Kitahama et al., 1994), group A3 is not found in sheep, in contrast to other species; group A4 is not clearly observed in sheep. In sheep, neuronal nuclei are not well evidenced; neurones of this group could therefore be intermingled with those of the locus coeruleus complex. In primates (Felten and Sladek, 1983; Pearson et al., 1983) the gatherings of groups A4, A6 and A7 appear to form a unique noradrenergic complex.

Noradrenergic neurones of group A5 are situated laterally around the emergence of the roots of the facial nerve. In sheep, this group is isolated from other noradrenergic groups, in contrast to its localization in rodents or primates, in which this group is rostrally contiguous with group A7 (Kitahama et al., 1994). In sheep, no DBH-IR neurones are found at the mid-portion of the motor trigeminal nucleus,

Neurones of groups A6 and A7 constitute the most rostral noradrenergic groups (Fig. 2e). Labelled neurones are found laterally on each side of the fourth ventricle, in the locus coeruleus (A6) and in the area around and above the superior cerebellar peduncles (A7). Unlike the situation in rats, the perikarya are not clustered in the locus coeruleus, but are scattered in a large area ventrolateral to the ventricle. This pattern of distribution is also observed in primates (Pearson ef al., 1983), cattle and pigs (Kitahama et al., 1994). According to this distribution, the different parts of the locus coeruleus described in rats are not found in sheep. As in other species, group A6 contains a greater density of cells containing noradrenaline than do other noradrenergic groups. In sheep, the boundaries between groups A6 and A7 are not clear and numerous perikarya containing noradrenaline are present between them. Most of them send their axons to the cerebral cortex, pons and medulla. Some of the neurones from group A6 project to the medial preoptic area (Tillet et al., 1993).

Adrenaline. Adrenergic neurones have been studied with anti-PNMT. In most species studied, two groups of PNMT-IR cells are observed in the caudal medulla oblongata, but in sheep a different pattern of central adrenergic innervation is found. It is characterized by the presence of only one group corresponding to the group $\mathrm{C} 2$ of the rat. Small PNMT-IR neurones are observed clustered ventrolaterally to the area postrema (Fig. $2 \mathrm{~g}$ ), and others are scattered around the tractus solitarius. PNMT-IR neurones are not found in the ventrolateral medulla, in the area corresponding to group CI. Such an exception is also observed in guinea-pigs, which lack both groups C1 and C2 and in which adrenaline cannot be detected biochemically (Cumming et al., 1986).

\section{Neuropeptides}

\section{Cholecystokinin}

In sheep, the distribution of cholecystokinin (CCK)-containing neurones (Fig. 3) has been studied with antisera raised against CCK8 which is the form commonly found in the central nervous system of other species; they are observed in all regions of the cerebral cortex, amygdala, hippocampus, lateral septal nucleus and bed nucleus of the stria terminalis (BNST) (Antonopoulos et al., 1987). Scattered neurones containing CCK are observed in the medial preoptic area, periventricular nucleus, $\mathrm{SCN}$, dorsocaudal hypothalamic area (Antonopoulos et al., 1987) and in the supraoptic nucleus (SON) (Marson et al., 1987). In the mesencephalon, CCK-IR cells are found in the central grey, laterally and ventrally to the cerebral aqueduct, in the raphe dorsalis and nucleus cuneiformis. In contrast to rats (Hökfelt et al., 1980), CCK-IR neurones are not found in the VTA of sheep. This observation makes questionable the 
SRIF

CCK

VIP

NT

NPY


ND
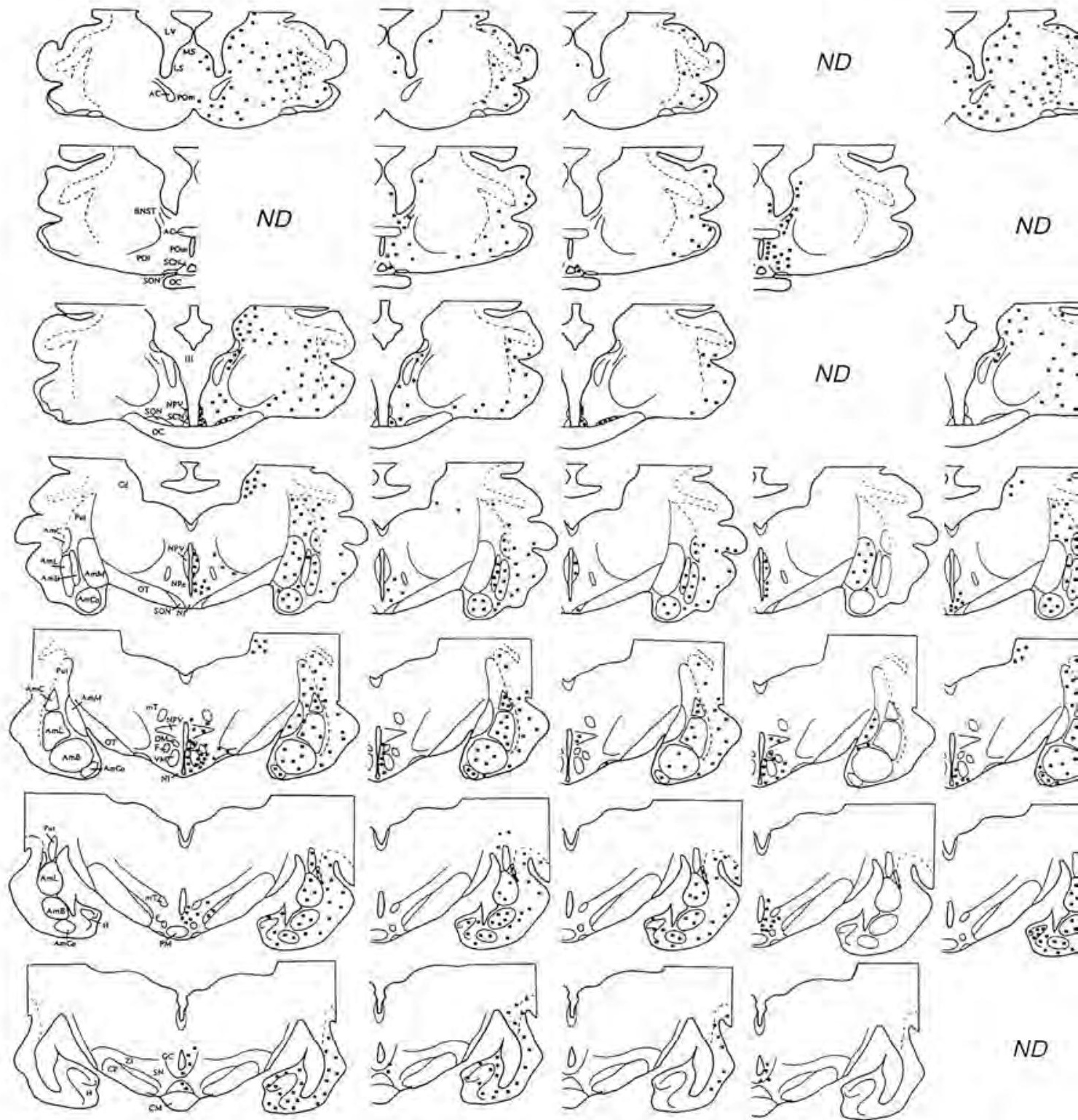

ND

ND

Fig. 3. Schematic drawings of successive frontal sections through the sheep brain, from rostral to caudal levels. Distribution of SRIF-, CCK-, VIP, NT- and NPY-IR neurones (adapted from Antonopoulos et al., 1987, 1989a; Papadopoulos et al. 1986a,b). ND: not drawn. For abbreviations, see Tablé 2.

occurrence of a CCK pathway from the VTA to mesolimbic forebrain in sheep. In the sheep pons, neurones containing CCK are observed in the dorsal tegmental nucleus and in the myelencephalon; they are found only in the nucleus of the tractus solitarius (NTS).

Compared with rats, sheep (even treated with colchicine) are thus characterized by the absence of CCK-containing cells in the hypothalamic paraventricular nucleus and in the infundibular nucleus, and by a restricted distribution in other brain areas, except the cortex. 


\section{$\begin{array}{lllll}\text { SRIF } & \text { CCK } & \text { VIP } & \text { NT } & \text { NPY }\end{array}$}
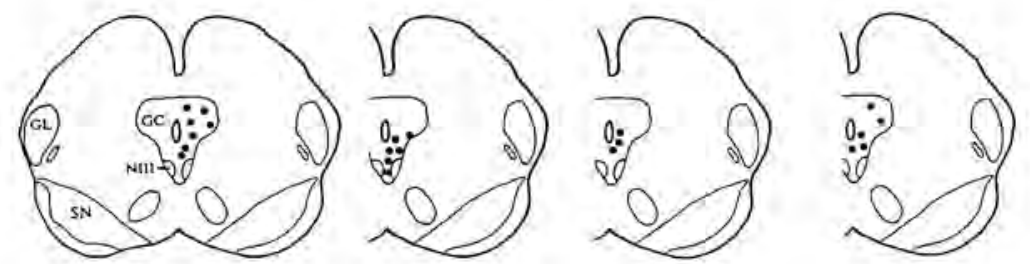

ND



ND

ND

ND
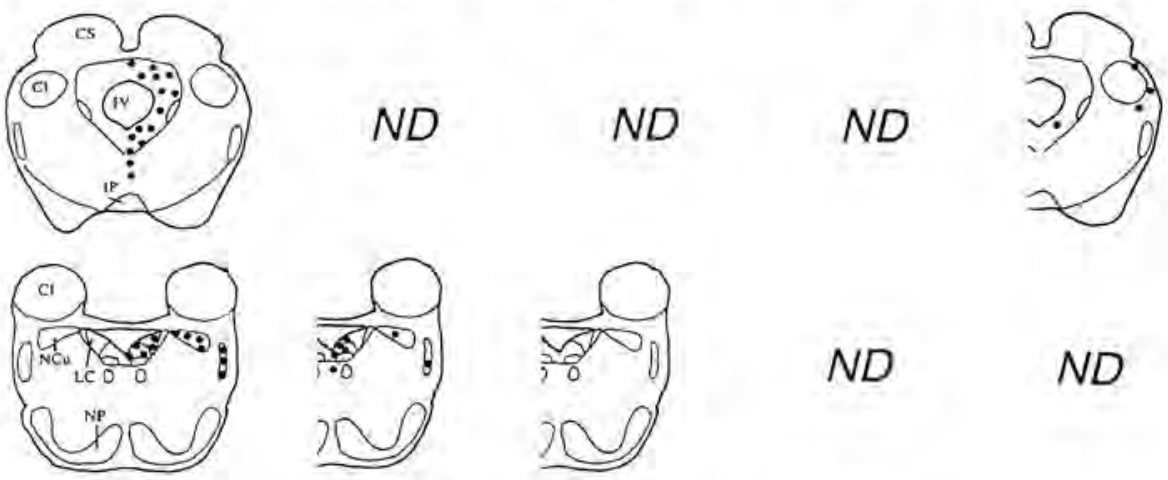

ND

ND


ND
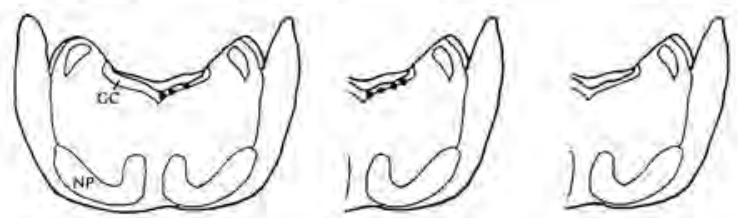

\section{ND}

ND


Fig. 3. Continued.

\section{Vasoactive intestinal peptide}

The distribution of vasoactive intestinal peptide (VIP) is similar to that of CCK (Fig. 3). In sheep (Table 1) as in rodents (Lorén et al., 1979), all regions of the cerebral cortex contain bipolar neurones. Since they are localized in the same layers, it has been suggested that both peptides could be colocalized in the same neurones of these areas (Antonopoulos et al., 1987). VIP-IR neurones are also observed in the sheep hippocampus and amygdala. In sheep, labelled neurones are observed in the SCN (Tillet $e t$ al., 1989b; Tessoneaud et al, 1994) as in rats, but, in addition, VIP is found in neurones of the PVN and SON as in cats (Obata-Tsuto et al., 1983). In contrast to most peptides, the other diencephalic nuclei do not contain VIP-IR cells. In the mesencephalon, labelled cells are found in the central grey in sheep and rats, but in contrast to rats, the myelencephalon of sheep is devoid of VIP-IR neurones. 


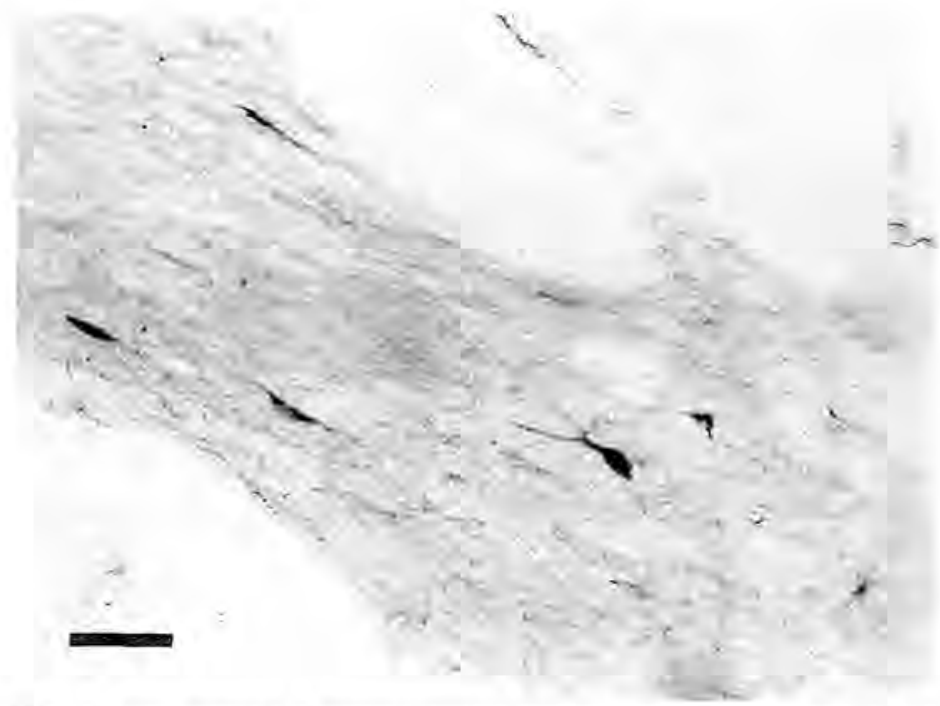

Fig. 4. Neuropeptide $Y$ immunoreactive neurones in the bed nucleus of the stria terminalis (BNST) of colchicine-treated sheep. Scale bar represents $50 \mu \mathrm{m}$.

\section{Neurotensin}

In sheep, neurotensin immunoreactive (NT-IR) neurones are visible in different parts of the brain only after colchicine pretreatment (Table I; Fig. 3). NT-IR neurones are observed in the lateral septal nucleus, BNST, ventromedial part of the caudate nucleus and medial amygdaloid nucleus. In the telencephalon, their distribution in sheep contrasts with that observed in rats (Roberts et al., 1982), as the central amygdaloid nucleus of sheep does not contain NT-IR neurones, whereas in rats, a large number of labelled neurones are found in this region. Most of the hypothalamic nuclei contain NT-IR neurones and the highest density is observed in the PVN. The periventricular nucleus of the thalamus also contains labelled neurones. In the brainstem, labelled neurones are distributed in the mesencephalic central grey. In the myelencephalon, few neurones are found in the pontine central grey area, locus coeruleus and NTS. In contrast to rats, NT-IR neurones are not found in the parabrachial nucleus and in the spinal cord. Another difference between the NT system of sheep and rats concerns the organization of limbic neurotensinergic inputs to the cortex. In rats, these fibres originate from the central amygdaloid and parabrachial nuclei (Jennes et al., 1982), but in sheep these nuclei are devoid of NT-IR neurones, and such afferents could have a different origin (Papadopoulos et al., 1986a).

\section{Neuropeptide $Y$}

Neuropeptide $Y$ immunoreactive (NPY-IR) neurones have been identified in sheep by immunohistochemistry in the different brain areas except the pons (Fig. 3) (Antonopoulos et al., 1989a). This description has been confirmed by in situ hybridization in the hypothalamus (McShane et al., 1993). Colchicine treatment increases the labelling intensity and the number of immunoreactive neurones. The cerebral cortex contains numerous labelled neurones in all laminae. In the telencephalon, immunoreactive perikarya are found in the striatum, claustrum, hippocampus, amygdaloid complex except the medial amygdaloid nucleus, septum and BNST (Fig, 4). In the diencephalon, labelled neurones are found in the infundibular nucleus and the surrounding areas using in situ hybridization and immunohistochemistry techniques. In the hindbrain, a lower density of immunoreactive perikarya is observed in the central grey, and in the dorsal and lateral part of the colliculi. In the medulla, immunoreactive neurones are present only in the NTS and ventrolateral medulla. Such a distribution showing a high density of immunoreactive perikarya in the forebrain and a low density in the hindbrain is also observed in rats (Chronwall et al., 1985) and monkeys (Smith et al., 1985). 


\section{Corticotrophin-releasing factor}

In sheep, corticotrophin-releasing factor (CRF) has been identified by immunohistochemistry and by in situ hybridization (Table 1). CRF immunoreactivity is present in the medial part of the PVN of the hypothalamus where the highest density of labelled perikarya is observed. In addition, mRNA encoding CRF has been detected in the ovine olivary nuclei of the brainstem and in some neurones scattered in every major cortical field, in the vicinity of the LC and the parabrachial nucleus and solitary tract (Matthews et al., 1991). In rats, all these structures contain CRF-IR neurones (Sakanaka et al., 1987). However, the distribution in sheep differs from that of rats, since no immunoreactive cells are observed in the amygdaloid nuclei, BNST, substantia inominata, in the dorsal tegmental field, mammillary and posterior hypothalamic nuclei. Another important difference between rats and sheep is the absence of CRF in the sheep SON. In rats, both CRF and its mRNA are identified in some neurones of the SON (Lightman and Young, 1987; Sakanaka et al., 1987). In sheep, CRF-IR neurones are less widely distributed than in rats. As in other species, a major projection of fibres is observed in the median eminence.

\section{Gonadotrophin releasing hormone}

In sheep, as in all the species studied, GnRH-IR neurones are not aggregated in discrete brain nuclei, but scattered throughout the preoptico-hypothalamic area (Fig. 5a). The concentration of GnRH in immunoreactive perikarya is quite high since pretreatment of the animals with colchicine is not required and does not modify the number of labelled neurones. Many studies have described the distribution of GnRH-IR perikarya (Table 1). Most of them are observed around the vascular organ of the lamina terminalis (OVLT) where $50 \%$ of the perikarya are observed (Fig. 5b) (Caldani et al., 1988). The most rostral extension is identified in the accessory olfactory bulb and the most caudal extension in the anterior part of the mammillary bodies. The mediobasal hypothalamus contains about $15 \%$ of the GnRH-IR neurones. The distribution of GnRH-IR perikarya in the ovine preoptic-anterior hypothalamic area is similar to that described in rodents (Barry et al, 1985). However, small species differences are observed; GnRH-IR cells are present in the SCN of guinea-pigs and hamsters but not of sheep. Compared with primates, the major difference concerns the mediobasal hypothalamus where the arcuate nucleus and surrounding areas present a large number of GnRH-IR perikarya, whereas few neurones are found here (less than 15\%) in sheep (Caldani et al., 1988).

GnRH perikarya in extrahypothalamic-preoptic areas represent only $5 \%$ of the population; they are observed in the amygdala and subcallosal area of ewes (Advis et al., 1985). This distribution matches that found in other species more extensively described in this respect. The GnRH distribution in sheep is characterized by a lower density than in other species: in monkeys it extends more posteriorly (Barry, 1978) and in hamsters, anterior extension appears more important (Jennes and Stumpf, 1980).

As in other species, GnRH neurones send a major projection to the median eminence, but also to the OVLT. Other GnRH pathways are also observed outside the preoptic-anterior hypothalamic areas, towards the olfactory bulb, amygdala, hippocampus and mesencephalon.

\section{Somatostatin}

Neurones containing somatostatin or somatotrophin inhibiting factor (SRIF)-IR can be observed without colchicine treatment, but this treatment allows additional labelled neurones to be visualized, particularly in the myelencephalon (Papadopoulos et al., 1986b) (Fig. 3). SRIF-IR neurones are observed in the different layers of all areas of the cerebral cortex. They are also found in the striatum (Fig. 6a), claustrum, different nuclei of the amygdala, hippocampus, lateral septal nucleus and BNST as in rats and humans. In the diencephalon, the periventricular nucleus of the preoptic area and the different nuclei of the hypothalamus contain various densities of labelled neurones. SRIF-IR neurones are found in the pars verticalis and horizontalis of the PVN as defined by Welento et al. (1969). Many labelled cells surround the ventromedial nucleus of the hypothalamus, which itself is devoid of them. The SON, SCN, infundibular nucleus, lateral preoptic area, dorsal and caudal hypothalamus also contain numerous SRIF-IR neurones. In the mesencephalon, labelled cells extend to the central grey, nucleus cuneiformis, superior central nucleus and dorsal raphe. However, their distribution in sheep is characterized by the 

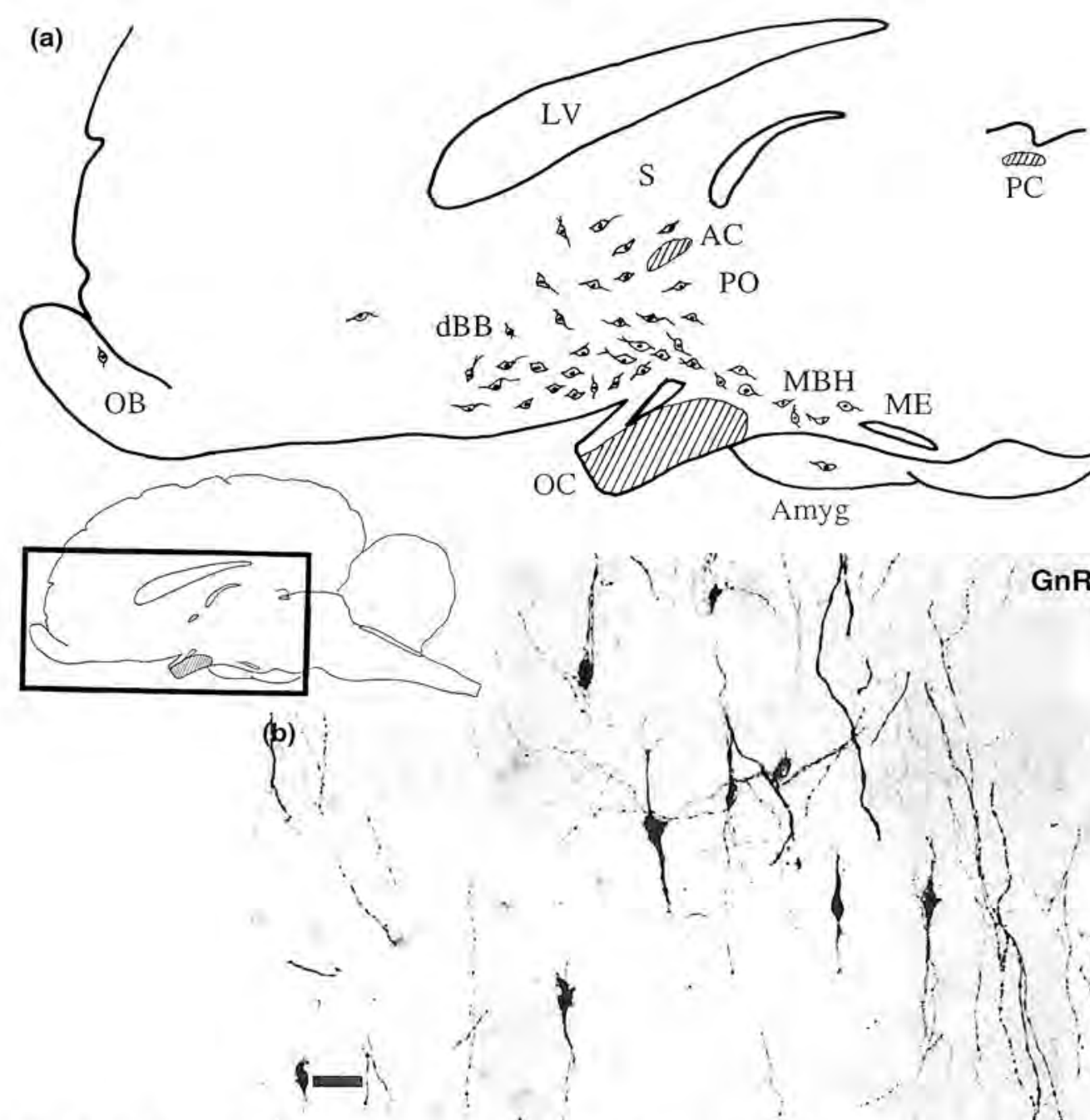

$$
\mathrm{PO}
$$



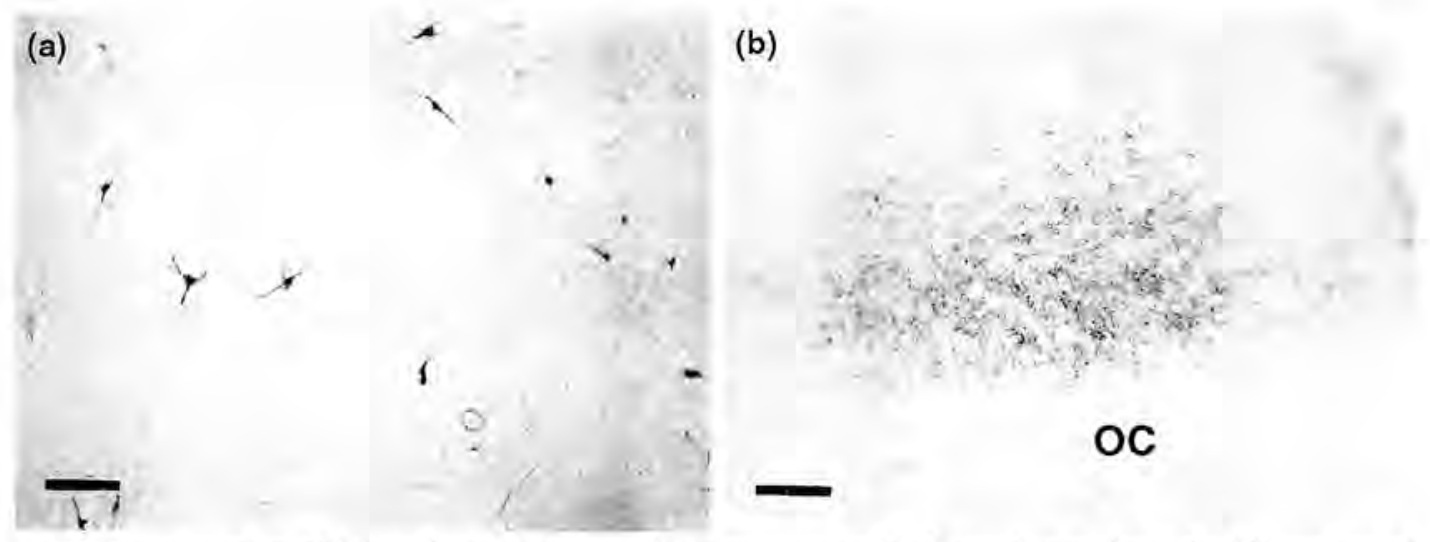

Fig. 6. Somatotrophin inhibiting factor (SRIF)-containing neurones in (a) the caudate nucleus of colchicine-treated animals. (b) The sheep suprachiasmatic nucleus $(\mathrm{SCN})$ is characterized by a dense network of met-enkephalin containing fibres. OC: optic chiasma. Scale bars represent $100 \mu \mathrm{m}$.

scattered. The morphology of the ovine SON and PVN differs from that of rats (Welento et al., 1969). In sheep the SON form a continuous structure extending along the ventral portion of the hypothalamus and covering the optic chiasma. Moreover, compared with rodents, the ovine accessory nuclei are found in the retrochiasmatic area. The sheep PVN is characterized by dorsal and ventral subgroups which join caudally in the posterior part of the nucleus. The dorsal part is similar to the PVN of rodents but the ventral part has no equivalent nucleus in rodents. The ventral part is also observed in goats and pigs (van Eerdenburg et al., 1990; Hamada et al., 1992).

Oxytocin. The distribution of neurones containing oxytocin has been studied by immunohistochemistry and in situ hybridization (Broad et al., 1993b). The largest population of labelled neurones is found in the SON and PVN, and a small number in the BNST, anterior commissural nucleus, and periventricular part of the preoptic area. In the PVN, oxytocin neurones are diffusely distributed throughout the nucleus (Papadopoulos et al., 1985). A similar distribution is observed in rats (Sofroniew, 1985).

Vasopressin. The AVP-IR neurones are distributed in the PVN and SON like those of oxytocin, but they constitute distinct populations (Watkins and Moore, 1983). In addition, AVP-IR neurones are found in the SCN after colchicine treatment (Tillet et al., 1989b). In the latter nucleus, in contrast to the PVN and SON, labelled cells are parvicellular. Although the distribution of neurones containing AVP has not been extensively studied in the sheep brain, this peptide is not as widely distributed as it is in rats. The rat lateral septum, amygdala and locus coeruleus contain AVP-IR cells, but in sheep these areas are devoid of neurones containing AVP and of neurophysin (carrier protein of AVP and oxytocin), at least in the animals that were not treated with colchicine ( $Y$. Tillet, unpublished data).

\section{Calcitonin-gene related peptide}

The distribution of calcitonin-gene related peptide immunoreactive (CGRP-IR) neurones has been demonstrated only in the forebrain of castrated ewes (Herbison et al., 1993a). The highest density of labelled neurones (magnocellular) is observed in the ventral division of the PVN, and a few are also found in the dorsal division of the nucleus and SON. Scattered smaller neurones are also found in the preoptic area, anterior hypothalamic area, basal hypothalamus and area of the stria terminalis. Compared with rats (Herbison, 1992), the density of labelled neurones in the preoptic area of sheep is low. The lateral border of the anterior hypothalamus contains a high density of labelled neurones in rats but is devoid of immunoreactive neurones in sheep. 
between TH-IR fibres and perikarya in the rat arcuate nucleus (Leranth et al., 1985) and monkey periventricular nucleus (Thind and Goldsmith, 1986).

Morphological relationships involving neuropeptides

In the preoptic area, close appositions have been observed between NPY terminals and GnRH-IR neurones (Tillet et al., I989a). Ultrastructural investigations confirm the presence of synaptic inputs between these elements (Norgren and Lehman, 1989).

In the PVN, oxytocin and CRF are colocalized in only very few neurones (approximately $1 \%$ of cells contain both peptides), whereas in rodents about $10-20 \%$ of oxytocin and CRF neurone populations express both peptides (Papadopoulos et al., 1985). In addition, most of the neurones containing VIP also contain CRF and SRIF is sometimes colocalized with oxytocin (Papadopoulos et al., 1990). However, SRIF and VIP, VIP and oxytocin, SRIF and CRF are never found in the same neurones of the sheep PVN (Papadopoulos et al., 1990). Such colocalizations are observed or suspected in other species (Hökfelt et al. 1987; Sawchenko et al., 1984). However, there could be interspecies variations, since CCK is not present in the sheep PVN (Antonopoulos et al., 1987) and therefore cannot be colocalized with oxytocin and CRF as shown in rats (Vanderhaegen et al., 1981; Mezey et al., 1986). Another peptide, bombesin, the distribution of which has not been mapped in the sheep brain, is colocalized with CRF in fibres of the median eminence (Giraud et al., 1987). This observation suggests the colocalization of both peptides in PVN neurones. These observations would indicate that pluripotentiality of neurones of the PVN is different in sheep and rats.

The infundibular nucleus presents extensive neurochemical heterogeneity and different neurones that exhibit a similar morphology. However, although this nucleus does not present the same compartmentation in sheep compared with rats, the different neurotransmitters are found in distinct subparts, and among the putative colocalizations studied, few are observed and concern neurones containing both SRIF and NPY (Antonopoulos et al., 1989b). Most neurones from this group project to the median eminence (except $\beta$-endorphin) as observed in rats. However, some differences should be noted: if NPY, SRIF and $\beta$-endorphin innervation of the median eminence is similar to that of rodents, few NT-IR fibres are found in sheep compared with rodents (Merchenthaler and Lennard, 1991).

\section{Conclusion}

The distribution of neurotransmitters in the sheep brain is different from that of rodents or primates, which are more commonly studied: first, the architecture of the sheep brain is extensive with scattered rather than clustered neurones as seen in rodents, and the morphology of the neurohypophyseal system comprising the PVN and SON is different. Second, within these structures the fine neurochemical organization presents some differences compared with other species: an extensive distribution of $5 \mathrm{HT}$ cells towards more lateral parts of the brainstem, a lower density of TH-IR neurones in the rostrodorsal diencephalon, and the absence of adrenergic neurones in the ventrolateral medulla. With respect to peptides, there are no NT neurones in the central amygdaloid and parabrachial nuclei and no CCK in the PVN and VTA, but a few GnRH-IR neurones are found in the mediobasal hypothalamus. All these differences induce variations in the projection fields and some brain areas of the sheep contain specific patterns of terminal organization. For example, the SCN exhibits a low density of 5HT- and NPY-IR fibres but a dense network of met-enkephalin fibres. Compared with that of other species, the sheep hypothalamus presents a noteworthy neurochemical diversity, and in addition to the different morphological interactions between neurotransmitters, several neuronal groups receive peripheral information through steroid hormones (see Herbison et al., this supplement).

All these differences underline the difficulties in extrapolating results obtained in species other than sheep. Comparison between species (from morphological and physiological points of view) should improve our understanding of neuronal regulations and, in this way, the sheep could constitute an alternative model to rodents or primates. All these morphological observations constitute steps necessary for further physiological investigations. 
The author wishes to thank J. Thibault (Collège de France, Paris) for his contribution to catècholamine studies, M. Caldani and M. Batailler (INRA, Nouzilly) for their help with peptide immunohistochemistry, G. Tramu (Université de Bordeaux) for his generous gift of anti-NPY, K. Kitahama (CNRS Lyon), J-C. Thiéry and B. Malpaux (INRA, Nouzilly) for their critical reading of the manuscript, A. Bouroche (INRA Jouy-en-Josas) for the revision of the English manuscript, and A. Béguey for photographic assistance. This work was partially supported by AKZO-Intervet International Company.

\section{References}

Advis JP, Kuljis RO and Dey GS (1985) Distribution of LHRH content and total LHRH-degrading activity (LHRH-DA) in the hypothalamus of the ewe Endocrinology 116 2410-2418

Antonopoulos I. Papadopoulos GC, Karamanlidis AN, Parnavelas JG, Dinopoulos A and Michaloudi H (1987) VIPand CCK-like-immunoreactive neurons in the hedgehog (Erinaceus etropaeus) and the sheep (Oois aries) brain Journal of Companitive Neurology 263 290-307

Antonopoulos I. Karamanlidis AN, Papadopoulos GC. Michaloudi H, Dinopoulos A and Parnavelas JG (1989a) Neuropeptide $Y$-like immunoreactive neurons in the hedgehog (Erinacens enropaeus) and the sheep (Ovis aries) brain Journal fuir Hirnforschung 30 349-360

Antonopoulos J. Papadopoulos GC. Karamanlidis AN and Michaloudi H (1989b) Distribution of neuropeptides in the infundibular nucleus of the sheep Neuropeptides 14 $121-128$

Barry I (1978) Septo-epithalamo-habenular LRF-reactive neurons in monkeys Brain Research 151 183-187

Barry J. Hoffman GE and Wray S (1985) LHRH-containing systems. In Handbook of Chemical Neuroanatomy Vol. 4 . GABA and Neuropeptides in the CNS Part I, pp $160 \hat{0}-215$ Eds A. Björklund and T. Hökfelt. Elsevier Science Publishers. Amsterdam

Batailler Midache D, Thibault J and Tillet $Y$ (1992) Immunohistochemical colocalization of tyrosine hydroxylase and estradiol receptors in the sheep arcuate nucleus Neuroscience Letters $146 \quad 125-130$

Broad KD, Kendrick KM, Sirinathsinghii DJS and Keverne B (1993a) Changes in pro-opiomelanocortine and preproenkephalin mRNA levels in the ovine brain during pregnancy, parturition and lactation and in response to oestrogen and progesterone Journal of Neuroendocrinology 5 $711-719$

Broad KD, Kendrick KM, Sirinathsinghji DJS and Keverne B (1093b) Changes in oxytocin immunoreactivity and mRNA expression in the sheep brain during pregnancy, parturition and lactation and in response to oestrogen and progesterone Journal of Nearoendocrinology 5 435-444

Caldani M, Batailler M, Thiéry J-C and Dubois M (1988) LHRHimmunoreactive structures in the sheep brain Histochemistry 89 129-139

Chronwall BM, DiMaffio DA, Massrai VJ. Pickel VM, Ruggiero DA and O'Donohue TL (1985) The anatomy of neuropeptide $\gamma$-containing neurons in rat brain Neuroscience 15 1159-1181

Clarke I, Jessop D, Millar R, Morris M, Bloom S, Lightman S, Coen CW, Lew R and Smith I (1993) Many peptides that are present in the external zone of the median eminence are not secreted into the hypophysial portal blood of sheep Neuroendocrinology $57765-775$
Cumming $\mathrm{P}$, Von Krosigk $\mathrm{M}_{\text {, }}$ Reiner $\mathrm{PB}$, McGeer EG and Vincent SR (1986) Absence of adrenaline neurons in the guinea pig brain: a combined immunohistochemical and high-performance liquid chromatography study Neuriscience Letters $63125-130$

Dahlstrom A and Fuxe K (1964) Evidence for the existence of monoamine containing neurons in the central nervous system I. Demonstration of monoamines in cell bodies of brainstem neurons Acta Physiologita Scandinavica 62 (Supplementum 232) 1-55

Davis BJ and Macrides F (1983) Tyrosine hydroxylase immunoreactive netrons and fibers in the olfactory system of the hamster Journal of Comparafive Neurology 214 $427-440$

Dees WL, Sorensen AM Jr. Kemp WM and McArthur NH (1981) Immunohistochemical localization of gonadotropinreleasing hormone $(\mathrm{G} \pi \mathrm{RH})$ in the brain and infundibulum of the sheep Cell and Tissue Research 215 $181-191$

Fallan JH and Leslie FM (1986) Distribution of dynorphin and enkephalin peptides in the rat brain Journal of Comparative Neurology 245 293-336

Felten DL and Sladek JR Jr (1983) Monoamine distribution in primate brain V. Monoaminergic nuclei: anatomy, pathways and local organization Brain Research Bullelin 10 171-284

Finley JCW, Maderdrut JL and Petrusz P (1981) The immunocytochemical localization of enkephalin in the central nervous system of the rat Joumal of Comparative Neturology $198541-565$

Giraud AS, Smith I and Rundle SE (1987) Distribution and molecular forms of immunoreactive bombesin in the ovine median eminence Molecular and Cellular Endocrinology $\mathbf{5 3}$ $245-250$

Glas JD, Mastran T and Nett TM (1986) Effects of estradiol and progesterone on the gonadotropir-releasing hormone ( $\mathrm{GnRH}$ )-immunoreactive neuronal system of the anoestrous ewe Brain Research 381 336-344

Hamada T, Shimmizu T, Ichikawa M and Mori Y (1992) Immunohistochemical study on gonadotropin-releasing hormone neurons in the shiba goat brain Jourmal of Reproduction and Development 38 133-142

Hamill GS, Olschowska JA, Lenn NJ and Jacobowitz DM (1984) The subnuclear distribution of substance P, cholecystokinin. vasoactive intestinal peptide, somatostatin, Leu-enkephalin, dopamine- $\beta$-hydroxylase, and serotonin in the rat interpedunculat nucleus Journal of Comparative Nenrology 226 580-596

Herbison AE (1992) Identification of a sexually dimorphic neuronal population immunoreactive for calcitonin-gene related peptide (CGRP) in the rat medial preoptic area Brain Research $591289-295$ 
Herbison AE, Robinson JE and Skinner DC (1993a) Calcitonin gene related peptide (CGRP): immunohistochemical identification of a neuropeptide synthesised by ventral paraventricular magnocellular neurones in the sheep Brain. Research 611 147-151

Herbison AE, Robinson JE and Skinner DC (1993b) Distribution of estrogen receptors-immunoreactive cells in the preoptic area of the ewe: co-localization with glutamic acid decarboxylase but not luteinizing hormone-releasing hormone Neuroendocrinology 57 751-759

Herbison AE (1995) Neurochemical identity of neurones expressing oestrogen and androgen receptors in sheep hypothalamus Joumal of Reproduction and Fertility Supplement $49271-283$

Hoffman GE, Melnyk V, Hayes T, Bennett-Clarke C and Fowler E (1978) Immunocytology of LHRH neurons. In BrainEndacrine Interaction, Vol. III. Neural Hornones and ReproducFion, pp 67-82 Eds DE Scott, GP Kozlowski and A Weindl. Karger, Basel

Hökfelt T, Skirboll L, Rehfeld IF, Goldstein M, Markey K and Dann $\mathrm{O}$ (1980) A subpopulation of mesencephalic dopamine neurons projecting to limbic areas contains a cholecystokinin-like peptide: evidence from immunohistochemistry combined with retrograde tracing Neuroscience 5 2093-2124

Hökfelt T, Martenson R, Björklund A, Kleinau S and Goldstein M (1984) Distributional maps of tyrosine-hydroxylaseimmunoreactive neurons in the rat brain. In Handbook of Chemical Neurounatomy. Vol. 2. Classical Netirotransmitters in the CNS, Part I, pp 277-379 Eds A Bjorklund and T Hökfelt. Elsevier Science Publishers, Amsterdam

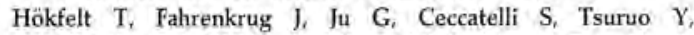
Meister B, Mutt V, Rundgren M, Brodin E, Terenius L, Hulting AL, Werner S, Björklund A and Vale W (1987) Analysis of peptide histidine-isoleucine/vasoactive intestinal polypeptide-immunoreactive neurons in the central nervous system with special reference to their relation to corticotropin releasing factors and enkephalin-like immunoreactivities in the paraventricular hypothalamic nucleus Neuroscience $23 \quad 827-857$

Hubbard JE and DiCarlo V (1974) Fluorescence histochemistry of monoamine containing cell bodies in the squirrel monkey (Saimini scitreus) III. Serotonin containing groups Journal of Compurative Neurology 143 385-398.

Inagaki S and Parent A (1985) Distribution of enkephalinimmunoreactive neurons in the forebrain and upper brainstem of the squirrel monkey Brain Research $359267-280$

Jennes L and Stumpf WE (1980) LHRH-systems in the brain of the golden hamster Cell and Tissue Research 209 $239-256$

Jennes L, Stumpf WE and Kalivas PW (1982) Neurotensin: topographical distribution in rat brain by immunohistochemistry Journal of Comparative Neurology 210 211-224

Jirikowski GF, Merchenthaler I, Rieger GE and Stumpf WE (1986) Estradiol target sites immunoreactive for $\beta$-endorphin in the arcuate nucleus of the rat and mouse hypothalamus Neuroscience Letters $65 \quad 121-126$

Johansson O, Hŏkfelt T and Elde RP (1984) Immunohistochemical distribution of somatostatin-like immunoreactivity in the central nervous system of the adult rat Neuroscience 13 265-339

Kawata M, Takeuchi Y, Ueda S, Matsuura T and Sano Y (1984) Immunohistochemical demonstration of serotonin contain- ing nerve fibers in the hypothalamus of the monkey, Macaca fuscata Cell and Tissue Research 236 495-503

Kendrick KM, Keverne EB, Hinton MR and Goode JA (1992) Oxytocin, amino acid and monoamine release in the region of the medial preoptic area and bed nucleus of the stria terminalis of the sheep during parturition and suckling Brain Research 569 199-209

Khachaturian H, Lewis ME, Tsou K and Watson SJ (1985) $\beta$-endorphin, alpha-MSH, $\mathrm{ACTH}$, and related peptides. In Handbook of Chemical Neuroanatomy Vol. 4: GABA and Neuropeptides in the CNS, Part 1. PP 216-273 Eds A Björklund and T Hökfelt. Elsevier Science Publishers. Amsterdam, New York, London

Kineman RD, Kraeling RR, Crim JW, Leshin LS, Barb CR and Rampacek GB (1989) Localization of proopiomelanocortin (POMC) immunoreactive neurons in the forebrain of the pig Biology of Reproduction $401119-1126$

Kiss J and Halász B (1985) Demonstration of serotonergic axons terminating on luteinizing hormone-releasing hormone neurons in the preoptic area of the rat using a combination of immunocytochemistry and high resolution autoradiography Neuroscience 14 ó-78

Kitahama K, Geffard M. Okamura H. Nagatsu I, Mons N and Jouvet M (1990) Dopamirie- and DOPA-immunoreactive neurons in the cat forebrain with reference to tyrosine hydroxylase-immunohistochemistry Brain Research 518 B3-94

Kitahama K, Nagatsu I and Pearson J (1994) Catecholarnine systems in mammalian midbrain and hindbrain: theme and variations. In Ploylogeny and Ontogenty in the Brain of Vertebrates, pP 183-205 Eds WJAJ Smeets and A Reiner. Cambridge University Press. Cambridge

Kolodziejczyk E, Baertschi AJ and Tramu G (1983) Corticoliberin-immunoreactive cell bodies localised in two distinct areas of the sheep hypothalamus Neuroscience 9 $26 \mathrm{I}-270$

Kuljis RO and Advis JP (1989) Immunocytochemical and physiological evidence of a synapse between dopamineand luteinizing hormone releasing hormone-containing neuroris in the ewe median eminence Endocrinology 124 1579-1581

Léger L and Descarries L (1978) Serotonin nerve terminals in the locus coeruleus of adult rat: a radioautographic study Brain Research 145 1-13

Léger L, Wiklund L, Descarries L and Persson M (1979) Description of an indolaminergic cell component in the cat locus coeruleus: a fluorescent histochemical and radioautographic study. Brain Resenrch 168 4.3-56

Lehman MN and Karsch FJ (1993) Do gonadotropin-releasing hormone, tyrosine hydroxylase-, and $\beta$-endorphinimmunoreactive neurons contain estrogen receptors? A double-label immunocytochemical study in the Suffolk ewe Endocrinology 133 887-895

Lehman MN, Robinson JE, Karsch FJ and Silverman AJ (1986) Immunocytochemical localization of luteinizing hormonereleasing hormone (LHRH) pathways in the sheep brain during anestrus and the mid-luteal phase of the estrous cycle Journal of Comparative Netirology 244 19-35

Lehman MN, Karsch FJ and Silverman AJ (1988) Potential sites of interaction between catecholamines and LHRH in the sheep brain Brain Research Bulletin 20 49-58

Leranth C, Sakamoto $\mathrm{H}$. Maclusky NJ, Shanabrough M and Naftolin F (1985) Intrinsic tyrosine hydroxylase (TH) immunoreactive axons synapse with $\mathrm{TH}$ immunopositive 
neurons in the rat arcuate nucleus Brain Research 331 $371-375$

Leshin LS, Rund LA, Crim JW and Kiser (1988) Immunacytochemical localization of luteinizing hormone-releasing hormone and proopiomelanocortin neurons within the preoptic area and hypothalamus of the bovine brain Biology of Reproduction 39 963-975

Lévy F, Guevara-Guzman R, Hinton MR, Kendrick KM and Keverne EB (1993) Effects of parturition and maternal experience on noradrenaline and acetylcholine release in the olfactory bulb of sheep Behavioral Neuroscience 107 $662-668$

Li YW, Halliday GM, Joh TH, Geffen LB and Blessing WW (1988) Tyrosine hydroxylase-containing neurons in the supraoptic and paraventricular nuclei of the adult human Brain Research $46175-86$

Lightman SL and Young WS III (1987) Vasopressin, oxytocin, dynorphin, enkephalin and corticotropin-releasing factor mRNA in the rat Journal of Plysiology 394 23-39

Lorén I. Emson PC. Fahrenkrug J. Bjorklund A, Alumet J, Hakanson R and Sundler F (1979) Distribution of vasoactive intestinal polypeptide in rat and mouse brain Neuroscience 4 I953-1976

Luppi PH, Sakai K, Salvert D, Bérod A and Jouvet M (1986) Periventricular dopaminergic neurons terminating in the neuro-intermediate lobe of the cat hypophysis journal of Comparative Neurology 244 204-212

McShane TM, Petersen SL, McCrone S and Keisler DH (1993) Influence of food restriction on neuropeptide- $Y$, proopiomelanocortin, and luteinizing hormone-releasing hormone gene expression in sheep hypothalami Biology of Reproduction $49831-839$

Marson L. Lauterio TJ. Della-Fera M-A and Baile CA (1987) Immunohistochemical distribution of cholecystokinin. dynophin $A$ and Met-enkephalin neurons in sheep hypothalamus Neuroscience Letter's 81 35-40

Matthews SG, Heavens RP and Sirinathsinghji DIS (1991) Cellular localisation of corticotropin releasing factor mRNA in the ovine brain Molecular Brain Research 11 $171-176$

Matthews SG, Heavens RP and Sirinathsinghit (1992) Distribution and cellular localization of preproenkephalin mRNA in the ovine brain and pituitary Molecular Brain Research 12 $349-355$

Merchenthaler I and Lennard DE (1991) The hypophysiotropic neurotensin-immunoreactive neuronal systern of the rat brain Endocrinology 129 2875-2880

Mezey E, Reisine TD, Skirboll L, Beinfeld M and Kiss JZ (1986) The role of cholecystokinin in corticotrophin-release: $\mathrm{CO}$ existence with vasopressin and corticotrophin-releasing factor in cell of the rat hypothalamic paraventricular nucleus Proceedings of the National Academy of Sciences USA 83 3510-3512

Morrell JI, McGinty JF and Pfaff DW (1985) A subset of beta-endorphin- or dynorphin containing neurons in the medial basal hypothalamus accumulates estradiol Neuroendocrinology $41417-420$

Nieuwenhuys R (1985) Chemoarchitecture of the Brain. SpringerVerlag, Berlin. Heidelberg, New York, Tokyo

Nitsos I and Rees S (1993) Development of immunoreactivity for calcitonin gene-related peptide, substance $P$ and glutamate in primary sensory neurons, and for serotonin in the spinal cord of fetal sheep Nesroscience $\mathbf{5 4}$ $239-252$
Norgren RB and Lehman MN (1989) A double-label preembedding immunoperoxidase technique for electron microscopy using diaminobenzidine and tetramethylbenzidine as markers Journal of Histochemistry and Cytochemistry $371283-1289$

Obata-Tsuto HL, Okamura H, Tsuto T, Terubayashi H, Fukui K, Yanaihara N and lbata Y (1983) Distribution of the VIP-like immunoreactive neurons in the cat central nervous system Brain Research Bulletin $10653-660$

Palkovits M, Brownstein MJ and Vale W (1983) Corticotropin releasing factor (CRF) immunoreactivity in hypothalamic and extrahypothalamic nuclei of sheep brain Neuroendocrinology $37 \quad 302-305$

Panayotacopoulou MT, Guntern R, Bouras C, Issidorides MR and Constantinidis J (1991) Tyrosine hydroxylaseimmunoreactive neurons in paraventricular and supraoptic nuclei of the human brain demonstrated by a method adapted to prolonged formalin fixation Journal of Neuroscience Methods 39 39-44

Papadopoulos GC, Karamanlidis AN, Michaloudi $\mathrm{H}$, Dinopoulos A, Antonopoulos J and Parnavelas JG (1985) The coexistence of oxytocin and corticotropin-releasing factor in the hypothalamus: an immunohistochemical study in the rat, sheep and hedgehog Neuroscience Letters 62 213-218

Papadopoulos GC, Karamanlidis AN, Antonopoulos J and Dinopoulos A (1986a) Neurotensin immunoreactive neurons in the hedgehog (Ermacens curopaeus) and the sheep (Ovis aries) central nervous system Jomnal of Comparative Neurology 244 193-203

Papadopoulos GC. Karamanlidis AN, Dinopoulos A and Antonopoulos J (19Sób) Somatostatin-like immunoreactive neurons in the hedgehog (Erinaceus eurvpaeus) and the sheep (Ovis aries) central nervous system Joumal of Com: parative Neurolegy 244 174-192

Papadopoulos GC, Antonopoulos I. Karamanlidis AN and Michaloudi H (1990) Coexistence of neuropeptides in the hypothalamic paraventricular nucleus of the sheep Neuropeptides $15 \quad 227-2.33$

Paull WK, Schöler J, Arimura A, Meyers CA, Chang JK, Chang D and Shimizu M (1982) Immunocytochemical localization of CRF in the ovine hypothalamus Peptides 1 183-191

Pearson J, Goldstein M, Markey K and Brandeis L (1983) Human brainstem catecholamine neuronal anatomy as indicated by immunohistochemistry with antibodies to tyrosine hydroxylase Neuroscience 8 3-32

Pearson J, Halliday G, Sakamoto N and Michel J-P (1990) Catecholaminergic neurons. In The Human Neroous System, pp 1023-1049 Ed. G Paxinos. Academic Press, San Diego

Petrusz P, Merchenthaler I and Maderdrut JL (1985) Distribution of enkephalin-containing neurons in the central nervous system. In Handbook of Chemical Neuromatomy Vol. 4: GABA and Neuropeptides in the CNS, Part 1, pp 273-334 Eds A Björklund and T Hökfeit. Elsevier Science Publishers, Amsterdam. New York, London

Polkowska J, Dubois MP and Domanski E (1980) Immunocytochemistry of luteinizing hormone releasing hormone (LHRH) in the sheep hypothalamus during various reproductive stages. Correlation with gonadotropic hormones in the pituitary Cell and Tissue Research 208 327-341

Roberts GW, Woodhams PL, Polak JM and Crow TJ (1982) Distribution of neuropeptides in the limbic system of the rat: the amygdaloid complex Neuroscience 7 99-131

Sakanaka M, Shibasaki T and Lederis K (1987) Corticotropin releasing factor-like immunoreactivity in the rat brain 
as revealed by a modified cobalt-glucose oxidasediaminobenzidine method Joumsl of Comparative Neurology $260 \quad 256-298$

Sakumoto T, Tohyama M, Sato K, Kimoto V. Kinugasa T, Tanizawa O, Kurachi K and Shimizu N (1978) Afferent fibre connections from the lower brain stem to hypothalamus studied by the horseradish peroxidase method with special reference to noradrenaline innervation Experimental Brain Research 31 81-94

Sar M (1983) Estradiol is concentrated in tyrosine hydroxylasecontaining neurons of the hypothalamus Science $\mathbf{2 2 3}$ 938-940

Sawchenko PE, Swanson LW and Vale WW (1984) Corticotrophin-releasing factor: co-expression within distinct subsets of oxytocin-, vasopressin- and neurotensinimmunoreactive neurons in the hypothalamus of the male rat Jourial of Neuroscience 4 1118-1129

Sladek JR and Walker P (1977) Serotonin containing neuronal perikarya in the primates locus coeruleus and subcoeruleus Bram Researd 134 359-366

Smith Y, Parent A, Kerkerian L and Pelletier G (1985) Distribution of neuropeptide $Y$ immunoreactivity in the basal forebrain and upper brainstem of the squirrel monkey (Saimiri sciureus) Journal of Comparative Neurology 236 $71-89$

Sofroniew MV (1985) Vasopressin; oxytocin and their related neurophysins. In Handbook of Chemical Neuroanatomy Vol. 4: GABA and Neuropeptides in the CNS, Part 1, pp 93-165 Eds A. Björklund and T. Hökfelt. Elsevier Science Publishers, Amsterdam, New York, London

Steinbusch HWM (1981) Distribution of serotonin-immunoreactivity in the central nervous system of the rat - cell bodies and terminals Neurostience $6557-618$

Tessoneaud A, Cooper HM, Caldani M, Locatelli A and Viguier-Martinez M-C (1994). The suprachiasmatic nucleus in the sheep: retinal projections and cytoarchitectural organization Cell and Tissue Research 278 65-84

Thind KK and Goldsmith PC (1986) Ultrastructural analysis of synapses involving tyrosine hydroxylase-containing neurons in the ventral periventricular hypothalamus of the macaque Brain Research 366 37-52

Tillet $Y$ (1987) Immunocytochemical localization of serotonincontaining neurons in the myelencephalon, brainstem and diencephalon of the sheep Neuroscience 23 501-527

Tillet $Y$ (1988) Adrenergic neurons in sheep brain demonstrated by immunohistochemistry with antibodies to pherylethanolamine $N$-methyltransferase (PNMT) and dopamine- $\beta$-hydroxylase $(\mathrm{DBH})$ : absence of the $\mathrm{C}_{1}$ cell group in the sheep brain Neuroscience Letters 95 107-112

Tillet $Y$ (1992) Serotoninergic projections from the raphe nuclei to the preoptic area in sheep as revealed by immunohistochemistry and retrograde labeling Journal of Comparalive Neurology 320 267-272

Tillet $\mathrm{Y}$ and Thibault J (1989) Catecholamine-containing neurons in the sheep brainstem and diencephalon: immuno- histochemical study with tyrosine hydroxylase $(\mathrm{TH})$ and dopamine- $\beta$-hydroxylase antibodies Joumal of Comparative Neurology $29069-104$

Tillet $\mathrm{Y}$ and Thibault J (1993) Morphological relationships between tyrosine hydroxylase immunoreactive neurons and dopamine-beta-hydroxylase immunoreactive fibres in dopamine cell group A15 of the sheep Journal of Chemical Neurocmatomy 6 69-78

Tillet Y, Thibault J and Dubois MP (1987) Immunohistochemical demonstration of the presence of catecholamine and serotonin neurons in the sheep olfactory bulb Neuroscience $\mathbf{2 0}$ 1011-1022

Tillet Y, Caldani M and Batailler M (1989a) Anatomical relationships of monoaminergic and neuropeptide $\gamma$-containing fibres with luteinizing hormone-releasing hormone systems in the preoptic area of the sheep brain: immunohistochemical studies Journal of Chemical Neuroanatomy 2 319-326

Tillet Y, Caldani M and Tramu G (1989b) Immunohistochemical characterization of the sheep suprachiasmatic nucleus. Journal of Chemical Neuroanatomy 2 215-226

Tillet Y, Batailler M, Krieger-Poullet M and Thibault J (1990) Presence of dopamine-immunoreactive cell bodies in the catecholaminergic group A15 of the sheep brain Hisfochemistry $93 \quad 327-333$

Tillet Y, Batailler M and Thibault J (1993) Neuronal projections. to the medial preoptic area of the sheep, with special reference to monoaminergic afferents. Immunohistochemical and retrograde tract tracing studies Joumal of Comparative Neurology 330 195-220

Tison F, Mons N, Geffard M and Henry P (1990) Immunohistochemistry of endogenous L-DOPA in the tat posterior hypothalamus Histochemistry $93655-660$

Ugrumov M, Hisano S and Daikoku S (1989) Topographic relations between tyrosine hydroxylase- and luteinizing hormone-releasing homone-immunoreactive fibers in the median eminence of adult rats Neuroscience Letters $\mathbf{1 0 2}$ 159-164

Vanderhaegen JJ. Lostra F, Vandesande F and Dierickx K (1981) Coexistence of cholecystokinin and oxytocin-neurophysin in some magnocellular hypothalamo-hypophyseal neurons Cell and Tissue Research $221227-231$

van Eerdenburg FJCM, Poot P, Molenaar GJ, van Leeuwen FW and Swaab DF (1990) A vasopressin and oxytocin containing nucleus in the pig hypothalamus that shows neuronal changes during puberty Journal of Comparative Neurology 301 138-146

Watkins WB and Moore LG (1983) Colocalization of oxytocin and neurophysin-1/1I and of vasopressin and neurophysin-III in neurons of the sheep hypothalamus. an immunohistochemical study Neurosciente Lelters $4 \mathrm{I}$ 67-71

Welento J, Szteyn S and Milart Z (1969) Observations on the stereotaxic configuration of the hypothalamus nuclej of the sheep Anatomischer Anzieger (Jena) I24 I-27 